\title{
Study on Cross-cultural Communication Competence Construction in English
}

\author{
Teaching \\ Lufang Wang \\ Xingtai University, Xingtai, 054001, China
}

\begin{abstract}
As economic globalization continuously popularizes and era develops, English has become the language which is most widely applied in the world. This puts forward new requirements for English teaching. Today when Chinese and foreign exchanges become increasingly close, cultivation of cross-cultural communication competence receives more and more attention. This has become the primary mission of English teaching and has been deeply pondered over by English teachers. The author firstly combines the work experience to summarize cross-cultural communication competence. Then, the author analyzes the importance of constructing cross-cultural communication competence in English teaching and mainly discusses the ways to construct cross-cultural communication competence in English teaching, in the hope of proving certain reference for English teaching.
\end{abstract}

Key words: English teaching; cross-culture; communication competence; construction

Since China joined WTO, English status in teaching activities has promoted significantly. Besides, higher requirements have been proposed for English teaching. Apart from imparting language knowledge, it is also required to cultivate students' ability to perceive and understand culture as well as construct cross-cultural communication competence. Students should expand their horizon, know very well foreign culture and enhance their cross-cultural communication competence while mastering language application ability in current stage, cross-cultural communication competence occupies an important position in English teaching. In order to construct cross-cultural communication competence in English teaching, we should comprehensively cognize cross-cultural communication competence.

\section{Overview of cross-cultural communication competence}

(I) Connotation of cross-cultural communication competence

Chinese and foreign scholars give different definitions for cross-cultural communication 
competence. Some wrong understandings exist inevitably. Chinese English teachers have made many researches on cross-cultural communication competence. Thus, cross-cultural communication competence is a major research content in language disciplines. In addition, the research range and contents are beyond language and teaching. Naturally, there is a wrong understanding that cross-cultural communication does not belong to the research field of foreign teachers. Moreover, cross-cultural communication competence covers many contents and has a wide coverage. The study in linguistics is just a part. This is another wrong understanding.

(II) Composition of cross-cultural communication competence

As for the composition of cross-cultural communication competence, there are differences due to individual differences. In China, the ideal gaining general support is that it consists of motivation, skills and theoretical knowledge. The construction of cross-cultural communication competence aims to cultivate students' language, behavior ability as well as pragmatics. Language refers to grammar, meaning, phonetic symbol and vocabulary. Behavior ability refers to communication competence and the ability of culture adaptation. Pragmatics refers to situation, social language, cultural background and discourse. These contents are relatively abstract. Chinese and foreign scholars have different emphases. Foreign scholars place particular emphasis on exchange and communication, while Chinese scholars lay particular stress on verbal communication. In English teaching, cross-cultural communication competence is a major training objective. Verbal communication is a main teaching task. To achieve this objective, favorable communication is required. Therefore, in the process of constructing cross-cultural communication competence, we should strictly refer to teaching programme and mainly cultivate students' daily communication, communication coordination ability and flexibility. 


\section{Importance of cross-cultural communication competence construction in English teaching}

We all know that language and culture of any country are different. Cross-cultural communication competence construction in English teaching can not just make students cognize some behaviors behind language culture and background. Then they can effectively apply then in actual cultural activities, excavate the essence and well analyze cultural and background differences of each country. As long as students grasp such ability, they can keep high sensitivity to different cultures. Secondly, cross-cultural communication competence construction also contributes to making students clearly know practical application ways of speeches and behaviors in different living situations and then correctly judge diverse behaviors. Besides, as talents in the new century, cross-cultural communication competence is a required basic ability. Corresponding cultural factors penetrate in all kinds of cultural backgrounds. Due to different orientations, certain differenced exist in thinking mode, social standards, values and daily life etc. Students should know very well cultural backgrounds of various countries, and explicitly cognize cultural differences. Value evaluation standards under diverse cultures have their respective rationality. Each value evaluation standard has no comparability. Only when students cognize this can they carry out cross-cultural communication in an effective and smooth way.

\section{Strengths and weaknesses of cross-cultural communication competence construction in English teaching}

(I) Strengths of cross-cultural communication competence construction in English teaching

In English teaching, cross-cultural communication competence construction is conducive to students to master English more deeply and then obtain favorable teaching effects. English is a type of language teaching, and also an art. To smoothly accomplish teaching tasks and achieve expected teaching objectives, it is required to thorough comprehend it from its connotation and essence. Language stems from culture. Although no fixed standard sand laws can be found in actual English communication, cultural background has rules to follow. If English teachers can make students grasp culture behind the language, students will master English more easily and fast. It thus can be known that cross-cultural communication competence construction is beneficial to gaining ideal teaching effects.

Secondly, cross-cultural communication competence construction provides more opportunities for exchange and interactions for teachers ad students and also injects vitality for teaching activities. 
Teaching activities in the new period pay more attention to innovation. Only active exploration and brave innovation can stimulate students' learning interest and learning desire. English belongs to a foreign language. Because foreign countries ad China have differences, students inevitably have emotions of resistance and boredom. However, students' thirst for knowledge is strong and full of curiosity for fresh things. Teachers should fully utilize this feature to rationally construct cross-cultural communication competence, improve students' participation in classroom, activate teaching atmosphere and finally boost English teaching quality.

\section{Cross-cultural communication competence construction in English teaching}

(I) Construction framework of cross-cultural communication competence

Through analyzing researches of Chinese and foreign experts and scholars on cross-cultural communication competence, it is known that cross-cultural communication competence mainly contains global consciousness, cultural knowledge, cultural debugging and daily communication.

1. Global consciousness includes cross-culture and beyond thinking. Specifically, cross-cultural awareness refers to sensitivity to native culture. There are main two forms: self-awareness and cultural relative consciousness. Self-awareness represents cognition degree for self ideological quality and values. This directly influences people's communication activities and reflects self-competence and control specifically. Beyond thinking refers to the ability to cognize and analyze different cultural phenomena. In diverse cultural backgrounds, cultural understanding generates due to communication differences; culture analysis ability generates due to cultural contrast and summary. Beyond thinking contributes to understanding and analysis of cultural diversity.

\section{Cultural knowledge}

Since cultural coverage is wide, this influences cross-cultural teaching to some extent. Usually, foreign teachers will divide culture into different parts. Learning cultural knowledge is only one constituent part of culture. Therefore, related experts and scholars consider during constructing cross-cultural communication competence, it is required to attach importance to learning cultural knowledge. Learning cultural knowledge is also a process of learning values. An excellent communicator can deeply cognize culture and then communicate smoothly only after mastering native culture and knowing foreign culture. In current stage, specific English teaching activities stress study of cultural knowledge. However, to construct cross-cultural communication 
competence, it is infeasible to purely depend on culture. This not merely restricts cultivation of high-quality talents, but also hinders development of cross-cultural communication competence.

\section{Cultural debugging}

Cultural debugging is a self-adjusting ability. This needs culture foundation and is closely related to psychological quality. It has direct influences on results of cross-cultural communication competence construction. Cultural debugging mainly contains psychological adjustment and flexible coping ability. Even with cultural diversity, one can quick adjust mental dynamics, reduce pressure and make physically and mentally pleased. Flexible coping capacity means one can flexibly apply language, relevant knowledge and method to cope with different contexts calmly.

\section{Daily communication}

Daily communication contains communication competence and strategy. Only when one masters and flexibly applies related abilities and strategies can he solve problems in real life in time. In daily communication, language is the fundamental communication tool, while related knowledge and skills are necessary conditions of flexibly applying language. Only with basic language knowledge, one can communicate smoothly. This is also a key content in English teaching. During constructing cross-cultural communication competence, language knowledge refers to customs and values. Besides, English teaching also explicitly stipulates learning skills. To cultivate students’ ability to comprehensively apply English is the main objective. Communication strategy is subordinate to communication ability. It refers to comprehensive display of communication skills in actual cross-cultural communication occasions. Besides, multiple factors should be considered, such as age, gender, social status and attitude of both communication parties.

\section{(II) Construction ways}

1. Rational application of communicative approach and computer technology

Communicative approach means in actual English teaching, teachers should try to create verbal communication environment close to real life, carry out communication activities with abundant and diversified activity forms and arouse learning interest. Large quantities of English teaching practices show traditional teaching methods cannot meet requirements of era development for talents. Communicative approach can effectively fill in the blank of traditional teaching method, further satisfy teaching requirements in the new period and enhance students' communication competence. With the development of science and technology, computer networking technology is 
widely applied in each field, including teaching activities. Film and television works reflect culture. So, English teachers should rationally apply computer to play some famous foreign film and television works for students. Through appreciating films, students can not just know life background and cultural customs of English-speaking countries, but also contribute to learning standard language. In addition, network environment contains rich teaching resources and owns the functions of fast information delivery and resource sharing. Schools and English teachers should pay attention to application and development of network resources, and guide students to rationally apply network in study.

\section{Cultural contrast}

The countries with different languages have cultural differences and diverse life experiences, which to some extent hinders language communication. Coupled with different national thinking modes and cognition levels, cultural communication fails. Thus, teachers should firstly eliminate language learning obstacles, correctly understand diverse systems of cultural value, clearly know cultural diversity, improve cross-cultural communication sensitivity and intensify cross-cultural communication awareness.

\section{Optimization of course teaching system}

To construct cross-cultural communication ability, language and culture courses should be set up in actual teaching activities. Besides, cultural factors should be gradually permeated and blended in course system to master cultural background of English-speaking countries and enhance communication ability. To learn a foreign language well, culture and knowledge are the foundation. Students should continuously accumulate and strength learning. Therefore, cross-cultural communication competence construction should be put into practice in actual teaching activities. During preparing foreign language teaching materials, it is required to rationally blend in national cultural background knowledge, add cross-cultural communication contents and effectively utilize existing resources to enhance language communication ability. For example, teachers should utilize the training room to simulate English communication language and implement communication and discussions in English. Compared with theory teaching in classroom, teaching effect of such mode has significant superiority. Moreover, teachers should try to provide more exchange opportunities for students, organize cultural exchange activities, carry out lectures, improve students' cultural sensitivity, promote their adaptive capacity, help them understand and master new knowledge 
rapidly. Finally, they may form cross-cultural communication awareness and enhance cross-cultural communication competence.

4. Construction of complete teaching and teaching material systems

With continuous improvement of society and overall promotion of educational reform, the position of cross-cultural communication competence stands out increasingly. However in current stage, the contents involving cross-cultural communication competence are few in English teaching. Cross-cultural communication competence can be implemented only through increasing teaching material construction force and rationally fusing cross-cultural communication knowledge. Teachers as the instructors and participants of teaching activities should tale active part in preparing teaching materials, give full play to their advantages to continuously adjust and optimize contents of teaching materials, construct complete teaching and teaching material systems in accordance with actual teaching requirements, pay high attention to cultural information reflected in teaching materials and collect related data so that students can know cultural diversity more easily, feel cultural differences and enhance cross-cultural communication competence.

\section{Conclusions}

Cross-cultural communication competence construction in English teaching can not only eliminate communication barriers, but expand life space and horizon. However, in English teaching, cross-cultural communication competence construction has certain advantages and disadvantages. This is a long-term and complex job. Cross-cultural communication competence construction needs many human resources and material resources. This will certainly increase educational cost. Hence, education sector and relevant personnel should realize the importance of cross-cultural communication competence construction. We should increase research and exploration force in this aspect, give full play to corresponding functions, continuously adjust and optimize course teaching system, enhance cross-cultural communication awareness and culture more integrated talents with cross-cultural communication competence for socialist modernization construction.

\section{References:}

[1] Zhang Fengna, Exploration of cross-cultural communication competence training in English teaching under background of cultural diversity [J]. Jiannan Literature, 2013,(6):218-218

[2] Liu Yuhong, Strategy research on cross-cultural communication competence training in English teaching [J]. Forward Position, 2012, (7):176-177 
[3] Yang Yali, Yang Fan, Study on training framework of cross-cultural communication competence for postgraduates of non-English major [J]. Heilongjiang Researches on Higher Education, 2013, 31(10):155-157

[4] Yi Zhen, Xu Lan and Wu meiyu et al., Study on cross-cultural communication competence mode for EFL course - from perspective of educators and learners [J]. Journal of Chengdu University, 2014, 28(3):78-82

[5] Fan Xiaohong, Research on application of cultural simulation method in cross-cultural communication training in English teaching - case study of English teaching in senior high schools [J]. Charming China, 2013, (22):218-219 